\title{
Pediatric postintensive care syndrome: high burden and a gap in evaluation tools for limited-resource settings
}

\author{
Chanapai Chaiyakulsil, MD ${ }^{1}$, Rapee Opasatian, MD $^{2}$, Paweethida Tippayawong, MD ${ }^{3}$ \\ ${ }^{1}$ Division of Pediatric Critical Care, Department of Pediatrics, Faculty of Medicine, Thammasat University, Prathumtani, Thailand; ${ }^{2}$ Division of Pediatric Pulmonology \\ and Critical Care, Department of Pediatrics, Lerdsin Hospital, Bangkok, Thailand; ${ }^{3}$ Department of Pediatrics, Thammasat University, Prathumtani, Thailand
}

This article aimed to summarize the impact and burden of pediatric postintensive care syndrome (PICS-p) in the physical, mental, cognitive, and social health domains after a review of the current pediatric literature in MEDLINE and PubMed. We also aimed to elucidate the limitations of the current evaluation tools used in limited-resource settings. PICS-p can impact a child's life for decades. Most validated tools are time-consuming, require qualifications, and expertise, are often limited to older children, and can evaluate only one domain. A novel, simple, and comprehensive surveillance tool can aid healthcare providers in the early detection and intervention of PICS-p. Further studies should validate and refine the parameters that will enhance the outcomes of pediatric intensive care unit survivors.

Key words: Child, Critical illness, Pediatric intensive care, Cognitive impairment, Posttraumatic stress disorder

\section{Key message}

Pediatric postintensive care syndrome has high impact and burden and can affect a child's life for decades. The early evaluation and detection of such problems require a simple and less time-consuming surveillance tool. Current evaluation tools can be difficult and strenuous for areas with limited resources. Thus, a new simple tool is required for the early detection and intervention of postintensive care syndrome in critically ill children.

\section{Introduction}

Millions of children worldwide experience critical illness that requires a pediatric intensive care unit (PICU) admission. With medical and technological advancements, mortality rates have decreased substantially. Nevertheless, in both adult and pediatric critical care, decreased mortality is often accompanied by increased morbidity. ${ }^{1-3)}$ Thus, mortality rate alone is no longer a measurement of success in patient care. In the 2010 Society of Critical Care Medicine Conference, a novel concept of postinten- sive care syndrome (PICS) was proposed and defined as "new or worsening impairments in physical, cognitive, or mental health status arising after critical illness and persisting beyond acute care hospitalization." Children admitted to the PICU were also classified as being at high risk of developing PICS. ${ }^{3,4)}$

Since that conference and a publication by Needham et al. ${ }^{3)}$ in 2012, significant attention has been directed toward detection and early interventions to improve PICS-related outcomes. ${ }^{4}$ Although PICS is well defined in the adult literature, data in pediatrics remain limited. Data concerning pediatric PICS (PICS-p) started to emerge after the systematic review by Herrup et al. ${ }^{5)}$ in 2017 and Watson et al. in 2018. ${ }^{6}$ Compared to adulthood, childhood is dynamic with heterogeneity in age, developmental milestones, social status, cognitive development, and physiologic capacities. Furthermore, children are also dependent on their family and caregivers. Thus, a conceptualizing framework concerning PICS-p was categorized by Manning et al. ${ }^{1)}$ in 2018 into physical, cognitive, mental, and social health domains. Many validated tools such as the Chalder Fatigue Scale, Health Utility Index (HUI), Strength and Difficulties Questionnaire, or Childrevised Impact of Event Scale were used in an attempt to detect PICS in children in different domains. A model was developed and utilized at St. Louis Children's Hospital and Doernbecher Children's Hospital to assess anxiety, depression, posttraumatic stress disorder (PTSD), and delirium in children admitted to the neurological critical care unit as well as their parents. This model consisted of several tools and checklists for use at baseline, PICU discharge, and hospital discharge as well as during outpatient visits. ${ }^{7)}$ As evidence of PICS-p started accumulating in the literature, it is of the utmost importance to explore the burden of such problems as well as the limitations of the current evaluation tools, especially in limited-resource settings. The main aim of this article was to summarize the impact and burden of PICS-p from the current pediatric literature in all 4 domains. The secondary aim was to discuss the problems with the current PICS-p evaluation tools.

Corresponding author: Chanapai Chaiyakulsil, MD, Division of Pediatric Critical Care, Department of Pediatrics, Faculty of Medicine, Thammasat University. 95 Phahol Yothin Road, Klong-Neung, Klong-Luang, Prathumthani 12120, Thailand

凶Email: chanapai.chai@hotmail.com, https://orcid.org/0000-0003-4677-4223

Received: 5 August, 2020, Revised: 10 November, 2020, Accepted: 2 December, 2020

This is an open-access article distributed under the terms of the Creative Commons Attribution Non-Commercial License (http://creativecommons.org/licenses/by$\mathrm{nc} / 4.0 /$ ) which permits unrestricted non-commercial use, distribution, and reproduction in any medium, provided the original work is properly cited.

Copyright (c) 2021 by The Korean Pediatric Society 


\section{Pediatric Post-Intensive Care Syndrome (PICS-p)}

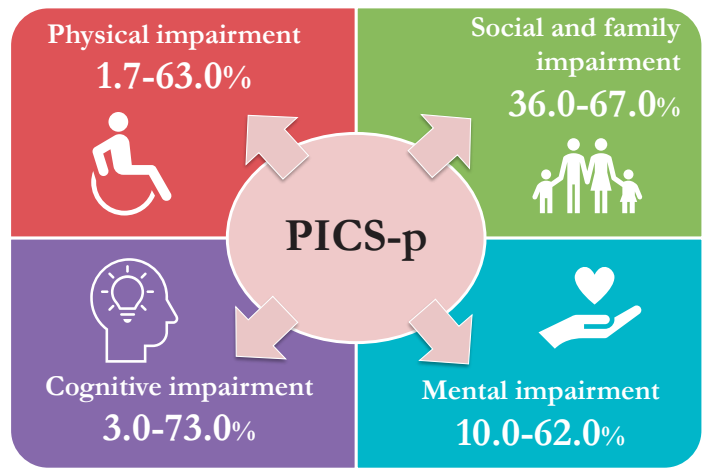

"The current evaluating tools are time-consuming, expertise-required, and often limited to older children. It should be comprehensive, simple, less timeconsuming, and applicable to all PICU survivors".

Graphic abstract

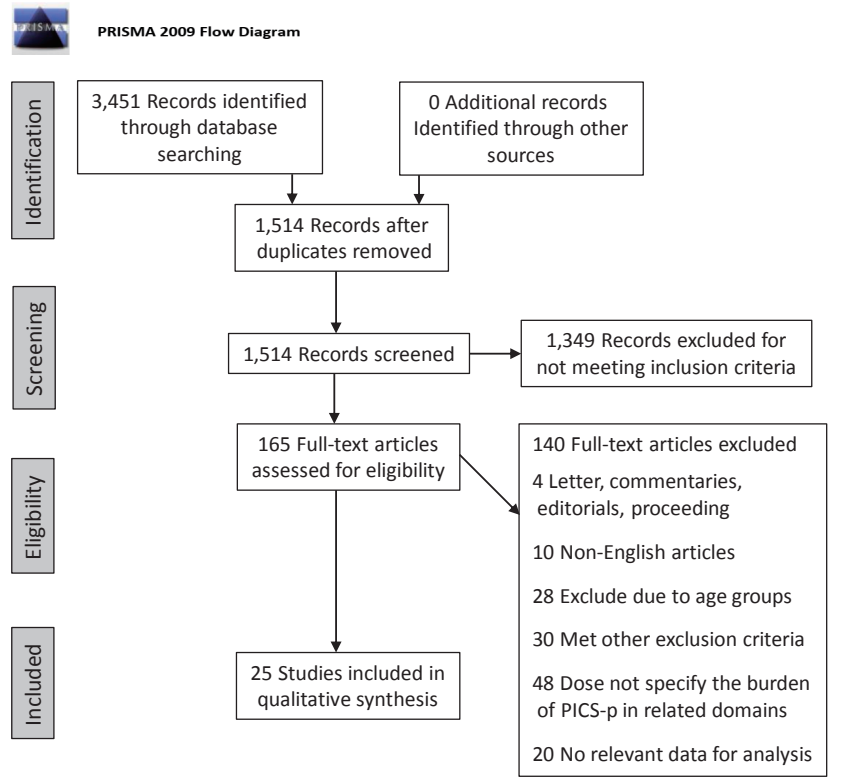

Fig. 1. PRISMA (Preferred Reporting Items for Systematic Reviews and Meta-Analyses) flow diagram. PICS, postintensive care syndrome.

\section{Methods}

This review article followed the Preferred Reporting Items for Systematic Reviews and Meta-Analysis Strategy for the selection of relevant articles (Fig. 1). The population, intervention, comparator, and outcome for this review were as follows: populationchildren aged 1 month to 18 years who were admitted to the PICU regardless of conditions and were evaluated for PICS-p, including family members caring for critically ill children; intervention/comparator-different PICS-p evaluation tools; and outcome-the burden of PICS-p in all 4 domains using different evaluation tools.

All retrospective, prospective, and cross-sectional studies evaluating the burden and morbidities of physical, cognitive, mental, and social health of the children surviving PICU stays as well as their families were included. Studies focusing on specific diseases, such as those of children admitted with neurologic diseases and congenital heart diseases, were also included for further elucidation of the burden of PICS-p in children. Due to the neurodevelopmental patterns and physiological differences from the PICU subpopulation, studies including neonates admitted to the neonatal intensive care unit were excluded.

A literature search was conducted of MEDLINE and PubMed in July 2020 using keywords and search terms. Two reviewers (CC and PT) were initially responsible for the eligibility evaluation. The reviews were performed independently. Agreement on the inclusion and exclusion of the studies was further discussed with the third reviewer (RO) in cases of disagreement. The search strategy and search terms are described in Supplementary material 1. Articles were included from database inception to the search timing. Only English-language articles were included in the analysis. Duplicate studies were excluded; letters, commentaries, editorials, guidelines, proceedings, conference abstracts, and case reports were also excluded from the analysis. Additionally, studies that did not specify definite age groups; included unclear populations or subgroups; or included adults without a subgroup analysis of pediatrics or unrelated to the family of critically ill children were excluded. Lastly, if the evaluation tools were not suitable for the age groups, such as those designed for adults or not fully validated, the articles were excluded from the analysis.

To fulfill the secondary study objective, qualitatively analyzed studies were further evaluated in terms of the tools used to quantify and evaluate PICS-p to identify possible limitations of current evaluation tools.

\section{Results}

After the removal of duplicates, a total of 1,514 search results 
were obtained. The abstracts were screened for relevance. At the end of the screening, approximately 165 articles were subjected to full-text review. Review articles were also evaluated for relevant data. After careful evaluation, 140 articles met the exclusion criteria and were excluded (Fig. 1). Thus, a total of 25 articles were qualitatively reviewed. The results are summarized by domain below.

\section{Physical and functional impairment}

Two systematic reviews, 5 prospective cohort studies, 1 descriptive study, and 1 database review were analyzed for physical and functional impairments. Studies demonstrated that physical impairments were $1.7 \%-63 \%$ in PICU survivors among different age groups using different evaluation tools. The impact of intensive care-acquired weakness and functional impairments is summarized in Table 1.8-14)

One systematic review and 1 pilot study were evaluated for sleep problems in PICU survivors. ${ }^{15,16)}$ A systematic review by Kudchadkar et al. ${ }^{15)}$ presented 9 cross-sectional studies concerning sleep in critically ill children, which demonstrated sleep fragmentation, increased stage 1 and stage 2 sleep, and decreased rapid eye movement sleep. Within this systematic review, a study by Gottschlich et al. ${ }^{17}$ ) demonstrated an absence of stage 3 and 4 sleep in $40 \%$ of polysomnographic periods with improvements upon recovery in PICU patients admitted with burns. Polysomnographic studies in mechanically ventilated children under neuromuscular blockade also showed sleep fragmentation and sleep stage distribution variations as well as significant circadian disruption. ${ }^{16)}$

Different studies used different evaluation tools to quantify physical impairments. Banwell et al. ${ }^{9)}$ used neuromuscular examination, Als et al. ${ }^{8}$ utilized the Chalder Fatigue Scale for physical evaluation, and 3 other studies utilized the HUI System. ${ }^{11-13)}$ The tools currently used to evaluate the physical and functional domain have certain problems. The Chalder Fatigue Scale, an 11-item Likert fatigue scale, measures the extent and severity of fatigue and differentiated tiredness from chronic fatigue syndrome. ${ }^{18,19)}$ Since this scale is a self-rating Likert scale, it is rather limited to older children and cannot detect problems in younger individuals. The HUI-2 and HUI-3 surveys evaluate 15 health attributes of 3-6 levels of abilities/disabilities. The HUI surveys can comprehensively assess patients with unique health statuses and provide an extensive framework to describe health status and health-related quality of life. ${ }^{20)}$ Nevertheless, the HUI has 2 major drawbacks. First, it is scored using single- or multipleattribute utility functions, which include look-up tables and mathematical formulas, making its use difficult in a busy setting. Second, use of the health status classification system based on the HUI is not suitable for children younger than 5 years of age.

\section{Cognitive health impairment}

A prospective observational study by Als et al. ${ }^{21)}$ revealed that PICU survivors scored lower on measures of verbal and visual recall, visual sustained attention, and working memory capacity, particularly the septic and neurologic disease cohort. Widespread cognitive impairments were found in younger children with lower socioeconomic status. A follow-up study demonstrated persistent impairments at 12 months despite improvements. ${ }^{22}$ Studies using the Pediatric Cerebral Performance Category revealed new cognitive problems in $3 \%-73 \%$ of survivors. ${ }^{23)}$ Among 29,352 PICU admissions from 24 virtual PICU sites, $3.4 \%$ of children demonstrated cognitive decline. ${ }^{24)}$

The Children Memory Scale used by Als et al. ${ }^{21,22)}$ was designed to comprehensively assess learning and memory in children and adolescents aged 5-16 years. The average time to complete this complete battery of tests was $30-40$ minutes. ${ }^{25)}$ Similar problems were also applied to the Weschler Abbreviated Scale of Intelligence used in a similar study. Despite its ability

Table 1. Impact of physical and functional impairments developed after pediatric intensive care unit stay

\begin{tabular}{|c|c|c|c|c|c|}
\hline Study & No. & Design & Age (yr) & Measurements & Findings \\
\hline Als et $a .^{8)}(2015)$ & $\begin{array}{c}88 \\
\text { (100 controls) }\end{array}$ & Prospective cohort & $5-16$ & $\begin{array}{l}\text { PICU admission > } 28 \text { days; Strengths } \\
\text { and Difficulties Questionnaire; } \\
\text { Chalder Fatigue Scale }\end{array}$ & $\begin{array}{l}\text { Risk of short-term physical } \\
\text { morbidity } 38 \% \text { vs. } 1 \% \text { control: } \\
\text { risk of fatigue }\end{array}$ \\
\hline Banwell et al. ${ }^{9}$ (2003) & 830 & Prospective cohort & $\begin{array}{l}3 \text { Months to } 17 \\
\text { years and } 11 \\
\text { months }\end{array}$ & Neuromuscular examination & $\begin{array}{l}\text { Generalized weakness: } 1.7 \% \\
\text { Significant weakness persists for } \\
\text { 3-12 months post ICU } \\
\text { discharge }\end{array}$ \\
\hline Fiser $^{10)}(1992)$ & 1,469 & Prospective cohort & Children & $\begin{array}{l}\text { Pediatric overall performance } \\
\text { category; Pediatric cerebral } \\
\text { performance category }\end{array}$ & $\begin{array}{l}\text { New global dysfunction in } 47 \% \text { of } \\
\text { children with normal baseline }\end{array}$ \\
\hline Gemke et al. ${ }^{11)}(1995)$ & 97 & Prospective cohort & Up to 16 & $\begin{array}{l}\text { Except infants; Multiattribute health } \\
\text { status classification }\end{array}$ & $\begin{array}{l}\text { Preserved functions in } 75 \% \text { of } \\
\text { patients }\end{array}$ \\
\hline Jones et al. ${ }^{12)}(2006)$ & 1,455 & Descriptive study & $>6$ Months & Health Utility Index 2 & $\begin{array}{l}63 \% \text { of children showed some } \\
\text { degree of impairments }\end{array}$ \\
\hline $\begin{array}{l}\text { Namachivayam et al. }{ }^{13)} \\
(2010)\end{array}$ & 4,010 & $\begin{array}{l}\text { Database review and } \\
\text { cohort study }\end{array}$ & All ages & $\begin{array}{l}\text { Health Status Utility Index and } \\
\text { Modified Glasgow Outcome Scale }\end{array}$ & $\begin{array}{l}\text { Children subgroup } \\
\text { Moderate-severe disability: } \\
8 \%(n=700 ; 1982) \\
18 \%(n=717 ; 2005)\end{array}$ \\
\hline Taylor et al. $(2003)^{14)}$ & 1,032 & Prospective cohort & $0-29$ & $\begin{array}{l}\text { Health Status Utility Index I and } \\
\text { Modified Glasgow Outcome Scale }\end{array}$ & $\begin{array}{l}29 \% \text { survived with disabilities } \\
10 \% \text { became dependent }\end{array}$ \\
\hline
\end{tabular}

ICU, intensive care unit; PICU, pediatric ICU. 
to assess specific and overall cognitive capabilities, its use is limited to children older than 6 years. It consists of 4 battery of subtests: vocabulary (31 items), block design (13 items), similarities (24 items), and matrix reasoning (30 items). ${ }^{26)}$ The use of these batteries might not be suitable for low-capacity areas. Furthermore, these tests are classified as level $\mathrm{C}$ measures, meaning that they must be administered and interpreted by individuals with a doctorate degree in psychology or related discipline. Examiners with a bachelor's degree in a related discipline might be able to conduct the test under supervision. ${ }^{25,26)}$

\section{Mental health impairment}

Children can experience mental health issues such as depression, anxiety, or even PTSD. Five prospective cohorts and 1 retrospective cohort revealed a substantial amount of mental impairment in critically ill children. ${ }^{27-32)}$ A prospective cohort study by Judge et al. ${ }^{30}$ ) illustrated that as high as $62 \%$ of PICU survivors experienced PTSD symptoms and 10\% were diag. nosed with probable PTSD. Another prospective study by Shears et al. ${ }^{32)}$ showed that $15 \%$ of critically ill children with meningococcal disease had PTSD. The data concerning the impact of mental impairment are summarized in Table 2. ${ }^{27-32)}$

\section{Social health and family}

Studies have shown that as high as $67 \%$ of family members suffered from depression during the first week of PICU admission and as high as 49\% experienced PTSD symptoms at 6 months. Approximately $36 \%$ of caretakers reported burden or overload within 2 months of the PICU admission. ${ }^{30,33-35)}$ A study by Shears et al. $^{32)}$ reported that $38 \%$ of mothers and $19 \%$ of fathers were at risk of developing PTSD as evidenced by higher maternal Impact of Events Scale Scores in the PICU.

The Impact of Event Scale, Strength and Difficulties Questionnaire, and Child Behavior Checklist are often used to evaluate the behavioral and psychological functions of children after critical illness. ${ }^{7,28,30-32)}$ These evaluation tools were mostly self- or parent-reported, were often restricted to older children, and can be time-consuming. ${ }^{36-38)}$

The evaluation tools and their disadvantages are described in Table 3 .

\section{Discussion}

Our study revealed the high impact and burden of PICS-p in critically ill children and demonstrated several problems with the current PICS-p evaluation tools.

As shown in the results within the physical and functional impairment domains, critically ill children are at high risk of developing intensive care-acquired weakness and sleep disruption. Intensive care-acquired weakness is described as acute symmetric muscle weakness in the extremities caused by critical illness. It can be classified as critical illness polyneuropathy, critical illness myopathy, critical illness neuromyopathy, and muscle deconditioning. ${ }^{33,39)}$ The etiologies are usually multifactorial but predominantly associated with excitation-contraction uncoupling, altered muscle biogenetics, and altered membrane excitability. ${ }^{40)}$ Its major risk factors include sepsis, prolonged mechanical ventilation, immobilization, glucocorticoids, and neuromuscular blocking agents. ${ }^{33)}$ Critically ill children are also exposed to multiple environmental, pharmacological, and physical factors that might lead to sleep disruption and poor sleep quality. Exposure to narcotics and sedatives decreases slow-wave sleep and rapid eye movement sleep. A systematic review of sleep in critically ill children by Kudchadkar et al. ${ }^{15)}$ demonstrated that critically ill children had sleep fragmentation and circadian disruption. Most studies utilized polysomnography to assess sleep quality and problems. This can be cumbersome in areas with limited availability of polysomnography and sleep technicians.

This article also demonstrated that critically ill children suffered from cognitive impairment and mental health dysfunction after intensive care unit discharge. Cognitive impairment can include deteriorations in memory, executive function, language, and visuospatial abilities. ${ }^{33)}$ Poor glycemic control, an admission diag. nosis of trauma, injury and poisoning, delirium, and in-hospital acute stress symptoms are risk factors for cognitive decline. ${ }^{7,33,41)}$ Children suffering from septic illness, experiencing higher numbers of invasive procedures and interventions, or receiving higher dosages of benzodiazepines and narcotics are at higher risk of experiencing mental health deterioration. . $^{5,3,42)}$

Not only did children experience functional deterioration, family caring for PICU survivors also suffered. The impact on

Table 2. Impact of mental impairments developed after pediatric intensive care unit stay

\begin{tabular}{|c|c|c|c|c|c|}
\hline Study & No. & Design & Age (yr) & Measurements & Findings \\
\hline $\begin{array}{l}\text { Bronner et al. }{ }^{27)} \\
\text { (2008) }\end{array}$ & 36 & Prospective cohort & $8-17$ & Dutch Children's Responses to Trauma Inventory & $\begin{array}{l}34.5 \% \text { - subclinical PTSD } \\
13.8 \% \text { - met criteria for PTSD }\end{array}$ \\
\hline $\begin{array}{l}\text { Colville et al. }{ }^{28)} \\
\text { (2012) }\end{array}$ & 66 & Prospective cohort & $7-17$ & ICU memory tool; Impact of Event Scale & $\begin{array}{l}3 \text { Months: } 32 \% \text { had PTSD } \\
12 \text { Months: } 26 \% \text { had PTSD }\end{array}$ \\
\hline $\begin{array}{l}\text { Dow et al. } \\
\text { (2013) }\end{array}$ & 59 & Prospective cohort & $6-16$ & Children's PTSD inventory & $17 \%-29 \%$ met the criteria for PTSD \\
\hline $\begin{array}{l}\text { Judge et al. }{ }^{30)} \\
\text { (2002) }\end{array}$ & 29 & Prospective cohort & $2-16$ & $\begin{array}{l}\text { Child Behavior Checklist; Strength and Difficul- } \\
\text { ties Questionnaire }\end{array}$ & $\begin{array}{l}\text { PTSD symptoms: } 62 \% \\
\text { Probable PTSD: } 10 \%\end{array}$ \\
\hline $\begin{array}{l}\text { Rees et al. }{ }^{31)} \\
(2004)\end{array}$ & 68 & Retrospective cohort & $5-18$ & Impact of Event Scale; PTSD scale for children & $\begin{array}{l}21 \% \text { of PICU patients suffered from PTSD } \\
\text { compared to } 0 \% \text { of general ward patients }\end{array}$ \\
\hline $\begin{array}{l}\text { Shears et al. }{ }^{32)} \\
(2005)\end{array}$ & 60 & Prospective cohort & $3-16$ & $\begin{array}{l}\text { Impact of Event Scale; Strength and Difficulties } \\
\text { Questionnaire }\end{array}$ & $15 \%$ has PTSD \\
\hline
\end{tabular}

PTSD, posttraumatic stress disorder; ICU, intensive care unit. 
Table 3. List of tools used to evaluate pediatric postintensive care syndrome and their possible limitations

\begin{tabular}{|c|c|c|c|c|}
\hline Evaluating tools & Domain & Type of tools & Age groups & Possible disadvantages \\
\hline Chalder Fatigue Scale ${ }^{18,19)}$ & Physical & $\begin{array}{l}\text { Eleven-item Likert Scale } \\
\text { Aim to differentiate tiredness from chronic } \\
\text { fatigue syndrome }\end{array}$ & $\begin{array}{l}\text { No specific age groups noted, } \\
\text { but likely older children and } \\
\text { adolescents ( }>7 \text { years old) }\end{array}$ & $\begin{array}{l}\text { Self-rating } \\
\text { Older child }\end{array}$ \\
\hline $\begin{array}{l}\text { Health Utility Index (HUI) } \\
\text { System }^{20)}\end{array}$ & $\begin{array}{l}\text { Physical } \\
\text { Mental } \\
\text { Emotional }\end{array}$ & $\begin{array}{l}\text { Scoring system using single attribute or } \\
\text { multiattribute utility tools } \\
\text { HUI- } 2: 7 \text { attributes ( } 3-5 \text { levels of abilities/ } \\
\text { disabilities) } \\
\text { HUI-3: } 8 \text { attributes (5- } 6 \text { levels of abilities/ } \\
\text { disabilities) } \\
\text { Comprehensively describe health status and } \\
\text { health-related quality of life }\end{array}$ & Older than 5 years old & $\begin{array}{l}\text { Requires tables and mathe- } \\
\text { matical formulas } \\
\text { Time-consuming } \\
\text { Aged-limited }\end{array}$ \\
\hline $\begin{array}{l}\text { Pediatric Cerebral Perfor- } \\
\text { mance Score } \\
\text { Pediatric Overall Perfor- } \\
\text { mance Category }\end{array}$ & $\begin{array}{l}\text { Cognitive } \\
\text { Physical }\end{array}$ & Six-level category scale & Children beyond neonatal period & Not fully comprehensive \\
\hline Children Memory Scale ${ }^{25)}$ & Cognitive & $\begin{array}{l}\text { Declarative learning and memory functions } \\
\text { Auditory/verbal; visual/nonverbal; attention/ } \\
\text { concentration }\end{array}$ & 5-16 years old & $\begin{array}{l}\text { Requires level } C \text { qualifications } \\
\text { Takes at least } 30-40 \text { minutes } \\
\text { Limited to older children }\end{array}$ \\
\hline $\begin{array}{l}\text { Weschler Abbreviated } \\
\text { Scale of Intelligence }\end{array}$ & Cognitive & $\begin{array}{l}\text { Four battery of subtests: vocabulary (31- } \\
\text { item), block design ( } 13 \text {-item), similarities } \\
\text { (24-item), and matrix reasoning (30-item) }\end{array}$ & At least 6 years of age & $\begin{array}{l}\text { Requires level } C \text { qualifications } \\
\text { Limited to older children } \\
\text { Time-consuming }\end{array}$ \\
\hline $\begin{array}{l}\text { Child-revised Impact of } \\
\text { Event Scale }\end{array}$ & Mental & $\begin{array}{l}\text { Self-reported 4-point scale screening for } \\
\text { posttraumatic stress disorder } \\
\text { CRIES-8: } 4 \text { items (intrusion); } 4 \text { items (avoi- } \\
\text { dance) } \\
\text { CRIES-13: additional } 5 \text { items for arousal }\end{array}$ & Children from $8-18$ years old & $\begin{array}{l}\text { Need to be able to read and } \\
\text { answer independently } \\
\text { Limited to older children }\end{array}$ \\
\hline $\begin{array}{l}\text { Strength and Difficulties } \\
\text { Questionnaire }^{37)}\end{array}$ & $\begin{array}{l}\text { Mental } \\
\text { Social }\end{array}$ & $\begin{array}{l}\text { Twenty-five items ( } 5 \text { items each for } 5 \text { scales) } \\
\text { Emotional; conduct; hyperactivity/inatten- } \\
\text { tion; peer relationship; social }\end{array}$ & $\begin{array}{l}\text { Self-completed: } 11-17 \text { years old } \\
\text { Parent/teacher completion: } 2- \\
17 \text { years old }\end{array}$ & $\begin{array}{l}\text { Time-consuming } \\
\text { Requires cooperation }\end{array}$ \\
\hline Child Behavior Checklist ${ }^{38)}$ & Mental & $\begin{array}{l}\text { Checklist consisting of } 113 \text { questions } \\
\text { scoring upon 3-point Likert scale }\end{array}$ & Children 6-18 years old & $\begin{array}{l}\text { Time-consuming } \\
\text { Requires cooperation } \\
\text { Limited to older children }\end{array}$ \\
\hline
\end{tabular}

CRIES, Children Revised Impact of Events Scale.

social health may include problems going back to school and getting along with peers and siblings, and caring for a sick child can have negative psychological effects. ${ }^{5,31)}$

In this review, the burden of PICS-p was elucidated in different domains via different prospective studies and review articles. Nevertheless, there were certain limitations to this review. There were vast differences in definitions, measurement tools, and follow-up timings among studies. Heterogeneity among study protocols might have led to underestimation and overestimation of the impact of PICS-p since some impairments might not be evident during the early phase of PICU discharge. These differences also posed problems in terms of when to assess which tests should be used, and how long these children should be followed up. As mentioned above, children demonstrate a diverse functional status related to age and developmental stage, and it is rather difficult to establish a preadmission baseline to demonstrate the full impact of PICS-p. As summarized in Table 3, most currently validated tools in the literature are time-consuming, require qualifications and expertise, are often applicable only to older children, and can evaluate only one domain. Children's cooperation also plays a role in the evaluation, making it difficult to obtain accurate results in a timely fashion. The Pediatric Cerebral Performance Score and Pediatric Overall Performance Category are 2 simple validated tests that were not time-consuming and did not require a high level of expertise. Nevertheless, these 2 tests are only concerned with functional and cognitive morbidity and are not fully comprehensive. A simple, cheap, less timeconsuming, and comprehensive surveillance tool that considers every domain and can be performed by everyone and in every child surviving a PICU stay is required for use in limited-resource settings.

In conclusion, PICS-p can impact a child's life for decades. Current evidence and evaluation tools have use limitations in limited-resource settings. Thus, a simple and novel surveillance tool is needed to aid healthcare providers in the early detection of and intervention for PICS-p.

\section{Footnotes}

Conflicts of interest: No potential conflict of interest relevant to this article was reported.

Acknowledgments: The author would like to show appreciation to the Department of Pediatrics, Faculty of Medicine, Thammasat University Hospital for the strong support and extensive cooperation in making this study possible. The author would also like to especially show a great appreciation to Professor Paskorn 
Sritipsukho, Department of Epidemiology, Faculty of Medicine, Thammasat University for the great advice in the improvement of this manuscript.

Supplementary material: Supplementary material 1 can be found via http://doi.org/10.3345/cep.2020.01354

\section{ORCID:}

Chanapai Chaiyakulsil (1) https://orcid.org/0000-0003-46774223

\section{References}

1. Manning JC, Pinto NP, Rennick JE, Colville G, Curley MAQ. Conceptualizing post intensive care syndrome in children-the PICS-p framework. Pediatr Crit Care Med 2018;19:298-300.

2. Pollack MM, Holubkov R, Funai T, Clark A, Berger JT, Meert K, et al. Pediatric intensive care outcomes: development of new morbidities during pediatric critical care. Pediatr Crit Care Med 2014;15:821-7.

3. Needham DM, Davidson J, Cohen H, Hopkins RO, Weinert C, Wunsch $\mathrm{H}$, et al. Improving long-term outcomes after discharge from intensive care unit: report from a stakeholders' conference. Crit Care Med 2012; 40:502-9.

4. Ekim A. The Post-Intensive care syndrome in children. Compr Child Adolesc Nurs 2020;43:15-21.

5. Herrup EA, Wieczorek B, Kudchadkar SR. Characteristics of postintensive care syndrome in survivors of pediatric critical illness: a systematic review. World J Crit Care Med 2017;6:124-34.

6. Watson RS, Choong K, Colville G, Crow S, Dervan LA, Hopkins RO, et al. Life after critical illness in children-toward an understanding of pediatric post-intensive care syndrome. J Pediatr 2018;198:16-24.

7. Hartman ME, Williams CN, Hall TA, Bosworth CC, Piantino JA. Postintensive-care syndrome for the pediatric neurologist. Pediatr Neurol 2020;108:47-53.

8. Als LC, Picouto MD, Hau SM, Nadel S, Cooper M, Pierce CM, et al. Mental and physical well-being following admission to pediatric intensive care. Pediatr Crit Care Med 2015;16:e141-9.

9. Banwell BL, Mildner RJ, Hassall AC, Becker LE, Vajsar J, Shemie SD. Muscle weakness in critically ill children. Neurology 2003;61:1779-82.

10. Fiser DH. Assessing the outcome of pediatric intensive care. J Pediatr 1992;121:68-74.

11. Gemke RJ, Bonsel GJ, van Vught AJ. Long-term survival and state of health after paediatric intensive care. Arch Dis Child 1995;73:196-201.

12. Jones S, Rantell K, Stevens K, Colwell B, Ratcliffe JR, Holland P, et al. Outcome at 6 months after admission for pediatric intensive care: a report of a national study of pediatric intensive care units in the United kingdom. Pediatrics 2006;118:2101-8.

13. Namachivayam P, Shann F, Shekerdemian L, Taylor A, van Sloten I, Delzoppo C, et al. Three decades of pediatric intensive care: who was admitted, what happened in intensive care, and what happened afterward. Pediatr Crit Care Med 2010;11:549-55.

14. Taylor A, Butt W, Ciardulli M. The functional outcome and quality of life of children after admission to an intensive care unit. Intensive Care Med 2003;29:795-800.

15. Kudchadkar SR, Aljohani OA, Punjabi NM. Sleep of critically ill children in the pediatric intensive care unit: a systematic review. Sleep Med Rev 2014;18:103-10.

16. Carno MA, Hoffman LA, Henker R, Carcillo J, Sanders MH. Sleep monitoring in children during neuromuscular blockade in the pediatric intensive care unit: a pilot study. Pediatr Crit Care Med 2004;5:224-9.

17. Gottschlich MM, Jenkins ME, Mayes T, Khoury J, Kramer M, Warden GD, et al. The 1994 Clinical Research Award. A prospective clinical study of the polysomnographic stages of sleep after burn injury. J Burn Care
Rehabil 1994;15:486-92.

18. Chalder T, Berelowitz G, Pawlikowska T, Watts L, Wessely S, Wright D, et al. Development of a fatigue scale. J Psychosom Res 1993;37:147-53.

19. Morriss RK, Wearden AJ, Mullis R. Exploring the validity of the Chalder Fatigue scale in chronic fatigue syndrome. J Psychosom Res 1998;45:4117.

20. Horsman J, Furlong W, Feeny D, Torrance G. The Health Utilities Index (HUI): concepts, measurement properties and applications. Health Qual Life Outcomes 2003;1:54.

21. Als LC, Nadel S, Cooper M, Pierce CM, Sahakian BJ, Garralda ME. Neuropsychologic function three to six months following admission to the PICU with meningoencephalitis, sepsis, and other disorders: a prospective study of school-aged children. Crit Care Med 2013;41:1094-103.

22. Als LC, Tennant A, Nadel S, Cooper M, Pierce CM, Garralda ME. Persistence of neuropsychological deficits following pediatric critical illness. Crit Care Med 2015;43:e312-5.

23. Ong C, Lee JH, Leow MK, Puthucheary ZA. Functional outcomes and physical impairments in pediatric critical care survivors: a scoping review. Pediatr Crit Care Med 2016;17:e247-59.

24. Bone MF, Feinglass JM, Goodman DM. Risk factors for acquiring functional and cognitive disabilities during admission to a PICU*. Pediatr Crit Care Med 2014;15:640-8.

25. Cohen MJ. Children's Memory Scale. In: Kreutzer JS, DeLuca J, Caplan B, editors. Encyclopedia of clinical neuropsychology 2011. New York: Springer; 2011 [cited 2020 Sep 15]. Available from: https://doi.org/10. 1007/978-0-387-79948-3 1532.

26. McCrimmon AW, Smith AD. Review of Weshcler Abbreviated Scale of Intelligence, second edition (WASI-II). J Psychoeduc Assess 2012;31:33741.

27. Bronner MB, Knoester H, Bos AP, Last BF, Grootenhuis MA. Posttraumatic stress disorder (PTSD) in children after paediatric intensive care treatment compared to children who survived a major fire disaster. Child Adolesc Psychiatry Ment Health 2008;2:9.

28. Colville G, Pierce C. Patterns of post-traumatic stress symptoms in families after paediatric intensive care. Intensive Care Med 2012;38:1523-31.

29. Dow BL, Kenardy JA, Le Brocque RM, Long DA. The diagnosis of posttraumatic stress disorder in school-aged children and adolescents following pediatric intensive care unit admission. J Child Adolesc Psychopharmacol 2013;23:614-9.

30. Judge D, Nadel S, Vergnaud S, Garralda ME. Psychiatric adjustment following meningococcal disease treated on a PICU. Intensive Care Med 2002;28:648-50.

31. Rees G, Gledhill J, Garralda ME, Nadel S. Psychiatric outcome following paediatric intensive care unit (PICU) admission: a cohort study. Intensive Care Med 2004;30:1607-14

32. Shears D, Nadel S, Gledhill J, Garralda ME. Short-term psychiatric adjustment of children and their parents following meningococcal disease. Pediatr Crit Care Med 2005;6:39-43.

33. Inoue S, Hatakeyama J, Kondo Y, Hifumi T, Sakuramoto H, Kawasaki T, et al. Post-intensive care syndrome: its pathophysiology, prevention, and future directions. Acute Med Surg 2019;6:233-46.

34. Harvey MA, Davidson JE. Postintensive care syndrome: right care, right now... and later. Crit Care Med 2016;44:381-5.

35. Haines KJ, Denehy L, Skinner EH, Warrillow S, Berney S. Psychosocial outcomes in informal caregivers of the critically ill: a systematic review. Crit Care Med 2015;43:1112-20.

36. Perrin S, Meiser-Stedman R, Smith P. The Children's Revised Impact of Event Scale (CRIES): validity as a screening instrument for PTSD. Behav Cogn Psychother 2005;33:487-98.

37. Goodman R. The Strengths and Difficulties Questionnaire: a research note. J Child Psychol Psychiatry 1997;38:581-6.

38. Achenbach TM. Manual for the Child Behavior Checklist/4-18 and 1991 profile. Burlington (VT): University of Vermont, Department of Psychiatry, 1991.

39. Farhan H, Moreno-Duarte I, Latronico N, Zafonte R, Eikermann M. Acquired muscle weakness in the surgical intensive care unit: nosology, epidemiology, diagnosis, and prevention. Anesthesiology 2016;124:207- 
34.

40. Batt J, Mathur S, Katzberg HD. Mechanism of ICU-acquired weakness: muscle contractility in critical illness. Intensive Care Med 2017;43:584-6.

41. Hopkins RO, Suchyta MR, Snow GL, Jephson A, Weaver LK, Orme JF. Blood glucose dysregulation and cognitive outcome in ARDS survivors. Brain Inj 2010;2:1478-84.

42. Colville G, Kerry S, Pierce C. Children's factual and delusional memories of intensive care. Am J Respir Crit Care Med 2008;177:976-82.
How to cite this article: Chaiyakulsil C, Opasatian R, Tippayawong P. Pediatric postintensive care syndrome: high burden and a gap in evaluation tools for limited-resource settings Clin Exp Pediatr 2021;64:436-42. https://doi.org/10.3345/ cep.2020.01354 


\title{
Supplementary material 1 . Search strategy for systematic review
}

The literature search strategy for the systematic review in order to assess the outcome of the burden of pediatric postintensive care syndrome (PICS-p) in all 4 domains (physical, cognitive, mental, and social health) using different evaluating tools is being outlined as follows. Articles were included from inception to current. Only English-language articles were included for analysis. All searches were conducted in July 2020.

\author{
The following databases were searched \\ 1. MEDLINE \\ 2. PUBMED \\ Databases were searched for types of review as follows: \\ 1. Retrospective cohort \\ 2. Prospective cohort \\ 3. Database review \\ 4. Systematic review \\ 5. Review articles \\ The following types of reviews were excluded from analysis: \\ 1. Letters \\ 2. Commentaries \\ 3. Editorials \\ 4. Guidelines \\ 5. Proceedings \\ 6. Conference abstracts \\ 7. Case reports
}

Controlled search terms according to Medical Subject Headings were used in combination with the specific search terms concerning the outcomes as follows:

Medical subject headings

1. Pediatric intensive care (OR) pediatric critical care

2. Critical illness (OR) Critical care (AND) children (OR) Pediatric

3. Post traumatic stress disorder

4. Cognitive impairment

\section{Specific search terms}

1. Pediatric critical illness survivors (OR) pediatric critical care survivors (OR) chidren critical illness (OR) Children critical care survivors

2. Pediatric postintensive care syndrome (OR) pediatric post-ICU syndrome

3. Physical impairment (OR) muscle weakness (OR) physical health

4. Sleep dysfunction (OR) sleep impairment (OR) sleep problems

5. Mental impairment

6. Cognitive impairment (OR) cognitive decline

7. Social impairment (OR) family burdens (OR) family problems

8. Posttraumatic stress disorder (OR) PTSD

The authors also took into account of synonyms, abbreviation, plurals of the search terms in order for the completeness of the data search. Synonyms such as decline, worsening, problems, or impacts were used interchangeably during search for impairments

\section{Synthesis of evidence}

Physical and functional impairments

5. Herrup EA, Wieczorek B, Kudchadkar SR. Characteristics of postintensive care syndrome in survivors of pediatric critical illness: A systematic review. World J Crit Care Med 2017;6:124-34.

6. Watson RS, Choong K, Colville G, Crow S, Dervan LA, Hopkins RO, et al. Life after Critical Illness in Children-Toward an Understanding of Pediatric Post-intensive Care Syndrome. J Pediatr 2018;198:16-24.

8. Als LC, Picouto MD, Hau SM, Nadel S, Cooper M, Pierce CM, et al. Mental and physical well-being following admission to pediatric 
intensive care. Pediatr Crit Care Med 2015;16:e141-9.

9. Banwell BL, Mildner RJ, Hassall AC, Becker LE, Vajsar J, Shemie SD. Muscle weakness in critically ill children. Neurology 2003;61:177982.

10. Fiser DH. Assessing the outcome of pediatric intensive care. J Pediatr 1992;121:68-74.

11. Gemke RJ, Bonsel GJ, van Vught AJ. Long-term survival and state of health after paediatric intensive care. Arch Dis Child 1995;73:196201.

12. Jones S, Rantell K, Stevens K, Colwell B, Ratcliffe JR, Holland P, et al. Outcome at 6 months after admission for pediatric intensive care: a report of a national study of pediatric intensive care units in the United kingdom. Pediatrics 2006;118:2101-8.

13. Namachivayam P, Shann F, Shekerdemian L, Taylor A, van Sloten I, Delzoppo C, et al. Three decades of pediatric intensive care: Who was admitted, what happened in intensive care, and what happened afterward. Pediatr Crit Care Med 2010;11:549-55.

14. Taylor A, Butt W, Ciardulli M. The functional outcome and quality of life of children after admission to an intensive care unit. Intensive Care Med 2003;29:795-800.

15. Kudchadkar SR, Aljohani OA, Punjabi NM. Sleep of critically ill children in the pediatric intensive care unit: a systematic review. Sleep Med Rev 2014;18:103-10.

16. Carno MA, Hoffman LA, Henker R, Carcillo J, Sanders MH. Sleep monitoring in children during neuromuscular blockade in the pediatric intensive care unit: a pilot study. Pediatr Crit Care Med 2004;5:224-9.

\section{Cognitive impairment}

21. Als LC, Nadel S, Cooper M, Pierce CM, Sahakian BJ, Garralda ME. Neuropsychologic function three to six months following admission to the PICU with meningoencephalitis, sepsis, and other disorders: a prospective study of school-aged children. Crit Care Med 2013;41:1094-103.

22. Als LC, Tennant A, Nadel S, Cooper M, Pierce CM, Garralda ME. Persistence of Neuropsychological Deficits Following Pediatric Critical Illness. Crit Care Med 2015;43:e312-5.

23. Ong C, Lee JH, Leow MK, Puthucheary ZA. Functional Outcomes and Physical Impairments in Pediatric Critical Care Survivors: A Scoping Review. Pediatr Crit Care Med 2016;17:e247-59.

24. Bone MF, Feinglass JM, Goodman DM. Risk factors for acquiring functional and cognitive disabilities during admission to a PICU*. Pediatr Crit Care Med 2014;15:640-8.

\section{Mental impairment}

27. Bronner MB, Knoester H, Bos AP, Last BF, Grootenhuis MA. Posttraumatic stress disorder (PTSD) in children after paediatric intensive care treatment compared to children who survived a major fire disaster. Child Adolesc Psychiatry Ment Health 2008;2:9.

28. Colville G, Pierce C. Patterns of posttraumatic stress symptoms in families after paediatric intensive care. Intensive Care Med 2012;38:1523-31.

29. Dow BL, Kenardy JA, Le Brocque RM, Long DA. The diagnosis of posttraumatic stress disorder in school-aged children and adolescents following pediatric intensive care unit admission. J Child Adolesc Psychopharmacol 2013;23:614-9.

30. Judge D, Nadel S, Vergnaud S, Garralda ME. Psychiatric adjustment following meningococcal disease treated on a PICU. Intensive Care Med 2002;28:648-50.

31. Rees G, Gledhill J, Garralda ME, Nadel S. Psychiatric outcome following paediatric intensive care unit (PICU) admission: a cohort study. Intensive Care Med 2004;30:1607-14.

32. Shears D, Nadel S, Gledhill J, Garralda ME. Short-term psychiatric adjustment of children and their parents following meningococcal disease. Pediatr Crit Care Med 2005;6:39-43.

42. Colville G, Kerry S, Pierce C. Children's factual and delusional memories of intensive care. Am J Respir Crit Care Med 2008;177:976-82.

\section{Social impairment}

33. Inoue S, Hatakeyama J, Kondo Y, Hifumi T, Sakuramoto H, Kawasaki T, et al. Post-intensive care syndrome: its pathophysiology, prevention, and future directions. Acute Med Surg 2019;6:233-46.

34. Harvey MA, Davidson JE. Postintensive Care Syndrome: Right Care, Right Now... and Later. Crit Care Med 2016;44:381-5.

35. Haines KJ, Denehy L, Skinner EH, Warrillow S, Berney S. Psychosocial outcomes in informal caregivers of the critically ill: a systematic review. Crit Care Med 2015;43:1112-20. 